\title{
Transgenic mice over-expressing carbonic anhydrase I showed aggravated joint inflammation and tissue destruction
}

\author{
Yabing Zheng ${ }^{1,2}$, Lin Wang ${ }^{2}$, Wei Zhang ${ }^{3}$, Hengwei $\mathrm{Xu}^{4}$ and Xiaotian Chang ${ }^{1 *}$
}

\begin{abstract}
Background: Studies have demonstrated that carbonic anhydrase I (CA1) stimulates calcium salt precipitation and cell calcification, which is an essential step in new bone formation. Our study had reported that CA1 encoding gene has a strong association with rheumatoid arthritis (RA) and ankylosing spondylitis (AS), two rheumatic diseases with abnormal new bone formation and bone resorption in joints. This study investigated the effect of CA1 on joint inflammation and tissue destruction in transgenic mice that over-express CA1 (CA1-Tg).

Methods: CA1-Tg was generated with C57BL/6J mice by conventional methods. CA1-Tg was treated with collagen-II to induce arthritis (CIA). Wild-type mice, CA1-Tg treated with bovine serum albumin (BSA) and transgenic mice over-expressing PADI4 (PADI4-Tg), a gene known to be involved in rheumatoid arthritis, were used as controls. Histochemistry and $\mathrm{X}$-ray radiographic assay were used to examine joint destruction. Western blotting and real time-PCR were used to examine CA1 expression.

Results: CIA was observed in 60\% of CA1-Tg, 20\% of PADI4-Tg and 20\% of wild-type mice after collagen injections. No CIA was found in CA1-Tg mice that received injections of BSA. The arthritic score was $5.5 \pm 0.84$ in the CA1-Tgs but the score was less than 2 in the injected wild-type mice and the PADI4-Tgs. The thickness of the hind paws in the CA1-Tgs was $3.46 \pm 0.11 \mathrm{~mm}$, which was thicker than that of PADI4-Tgs $(2.23 \pm 0.08 \mathrm{~mm})$, wild-type mice $(2.08 \pm 0.06 \mathrm{~mm})$ and BSA-treated CA1-Tgs $(2.04 \pm 0.07 \mathrm{~mm})$. Histochemistry showed obvious inflammation, synovial hyperplasia and bone destruction in the joints of CA1-Tg that was not detected in PADI4-Tgs or wild-type mice. $X$-ray assays showed bone fusion in the paws and spines of CA1-Tg mice.
\end{abstract}

Conclusion: Over-expression of CA1 may aggravate joint inflammation and tissue destruction in the transgenic mice.

Keywords: Carbonic anhydrase I (CA1), New bone formation, Transgenic mice, collagen-induced arthritis (CIA), Ankylosing spondylitis (AS), Rheumatoid arthritis (RA)

\section{Background}

Abnormal new bone formation and bone resorption are the most distinctive features of ankylosing spondylitis (AS) [1-3]. Histopathological experiments have demonstrated that severe forms of AS correlate significantly with villous chronic synovitis, including obliterating vascularitis, fibrosclerosis, necrosis and calcification of disintegrated synovial structures [4]. Using a proteomic

\footnotetext{
*Correspondence: changxt@126.com

'Medical Research Center of Shandong Provincial Qianfoshan Hospital, Shandong University, Jingshi road 16766, Jinan, Shandong 250014, P. R. China

Full list of author information is available at the end of the article
}

approach, we previously screened novel AS-specific proteins by simultaneously comparing the expression profiles of synovial membranes from patients with AS, rheumatoid arthritis (RA) and osteoarthritis (OA). That proteomic study revealed significantly increased expression of carbonic anhydrase I (CA1) in the synovial membrane of AS patients compared with those of RA and OA patients. Immunohistochemistry and western blotting analyses confirmed the above findings [5]. Furthermore, we also reported that methazolamide, an anti-CA drug, may improve AS symptoms by a case report [6]. CA1 is a member of the carbonic anhydrase (CA) family, 
and it catalyzes the reversible hydration and dehydration reactions of $\mathrm{CO}_{2} / \mathrm{H}_{2} \mathrm{CO}_{3}$ [7]. In vitro assays have demonstrated that $\mathrm{CA} 1$ not only enhances the hydration reaction but also promotes the formation of $\mathrm{CaCO}_{3}$ $[8,9]$. Calcium salt precipitation is an important step in bone formation. Thus, the increased CA1 expression in the synovium of AS patients may lead to improper mineralization by accelerating calcium salt deposition [5]. We recently found that an increased expression of CA1 stimulates calcium precipitation and ossification in cultured Saos- 2 cells, a human osteosarcoma cell line [10]. We also found significant association between the CA1 DNA polymorphism and susceptibility to AS risk that the gene encoding CA1 is susceptible to AS and RA risk. However, no study has demonstrated a role for CA1 over-expression in the processes of new bone formation and bone resorption of joint tissue in physiological condition.

In this study, we generated transgenic mice that overexpressed CA1 (CA1-Tg) and injected the animals with collagen II (cII) to induce arthritis (CIA). We examined the clinical score, arthritic incidence and footpad swelling in CA1-Tg mice, and we used wild-type mice and transgenic mice that over-express PADI4 (PADI4-Tg), a gene known to be involved in RA [11], as controls. X-ray assays and histochemistry were employed to examine joint destruction in these mice. The purpose of this study was to use transgenic mice to determine the effect of CA1 over-expression on joint inflammation and tissue destruction.

\section{Methods}

\section{Generation of transgenic mice that over-expressed CA1}

Mouse full-length CA1 cDNA was amplified by reverse transcription PCR (RT-PCR) using a kit from Invitrogen (USA) and confirmed by sequencing analysis. The CA1 cDNA was inserted downstream of the CMV promoter in the pCDNA3.1 $(+)$ vector between the BamHI and XhoI cloning sites. The completed plasmid was linearized by digestion with endonuclease BglII. The entire transgenic expression cassette including the CMV promoter, the CA1 full-length cDNA and the BGH polyA signal was not disrupted. The DNA fragments were gelpurified, dissolved in Tris-HCl-EDTA at a final concentration of $5 \mathrm{ng} / \mu \mathrm{l}$ and injected into the pronuclei of fertilized zygotes harvested from C57BL/6 mice using conventional methods to generate the transgenic mice [12]. This experiment was completed in Dr. Zhang Lianfeng's laboratory at the Institute of Laboratory Animal Science at the Chinese Academy of Medical Sciences.

The transgenic founder (F0) mice were mated with wild-type $\mathrm{C} 57 \mathrm{BL} / 6 \mathrm{~J}$ mice to produce the $\mathrm{F} 1$ generation, and CA1 expression was detected in the F1 transgenic mice. The F1 transgenic lines were mated with wild-type
C57BL/6J mice to produce F2 mice, which were used for phenotypic analyses. The wild-type mice were also obtained from Institute of Laboratory Animal Science at the Chinese Academy of Medical Sciences. The transgenic mice that over-expressed PADI4 were generated in the same manner.

Mouse genomic DNA was extracted from tail biopsies. PCR was performed in a $20 \mu \mathrm{l}$ reaction volume containing $1 \mu \mathrm{g}$ of genomic DNA and the primers used for cloning the CA1 gene. The sense primer was $5^{\prime}$-GCAAGCTT CATGAGACCTAGAATGAAGTAT- ${ }^{\prime}$, and the antisense primer was $5^{\prime}$-CGGGATCCTTTACTGCATTAGATTTT CGAG-3'. These primers amplify a 374 bp sequence from the pCMV promoter. The PCR product was examined using electrophoresis on $1 \%$ agarose gel.

Synovial tissues were dissected from CA1-Tg $(n=5)$, PADI4-Tg $(n=6)$ and wild-type $(n=6)$ mice. CA1 mRNA expression was quantified using real-time PCR. The thymus, spleen, liver, lungs and kidneys were dissected from CA1-Tg $(n=5)$, PADI4-Tg $(n=6)$ and wildtype mice. The levels of CA1 protein in these organs were examined using western blotting.

The procedures involving animals were approved by the Institutional Animal Care and Use Committee of the Chinese Institute of Laboratory Animal Science (GC-082018), and the mice were housed in an Association for Assessment and Accreditation of Laboratory Animal Care (AAALAC)-accredited facility. The Ethics Committee of Shandong Provincial Qianfoshan Hospital approved the study and the protocol.

\section{Collagen-induced arthritis}

Bovine collagen type II (cII) (400 $\mu$ g, Sigma, USA) was injected into the tails of CA1-Tg $(\mathrm{n}=10)$, PADI4-Tg $(\mathrm{n}=10)$ and wild-type $(\mathrm{n}=10)$ mice ( 8 weeks old, male). CA1- $\operatorname{Tg}(\mathrm{n}=10)$ were also treated with bovine serum albumin (BSA) as controls. cII was dissolved overnight at $4^{\circ} \mathrm{C}$ in $10 \mathrm{mM}$ acetic acid at a concentration $4 \mathrm{mg} / \mathrm{ml}$ and emulsified in an equal volume of complete Freund's adjuvant (CFA, Sigma, USA) containing $100 \mathrm{mg}$ heatkilled (strain H37Ra, Sigma, USA). These mice were injected with the same dose of cII in incomplete Freund's adjuvant (IFA, Sigma) 3 weeks later. The severity of CIA was determined by monitoring the incidence of CIA, the clinical score and the thickness of the hind paws. The incidence was expressed as the percentage of mice that showed visible symptoms of arthritis. Clinical scoring was performed using an established scoring system as described in Von Delwig's study [13]. The score for each paw was based on the degree of swelling and periarticular erythema using a scale of $0-3$ as follows: 0 = no evidence of erythema or swelling, $1=$ erythema confined to one joint region only, $2=$ erythema and swelling limited to one joint region only and $3=$ severe 
erythema and swelling extending from the ankle to the midfoot (tarsal) joint and involving both joint regions. Scores from all four paws were added to provide the total score for each mouse. The maximum possible score per mouse was 12. The thickness of the hind paws was measured using vernier calipers (reading error of $0.1 \mathrm{~mm}$, Mitutoyo, JAP). Control-treated CA1-Tg $(\mathrm{n}=10)$ mice were administered with BSA.

The development of disease was monitored for the period indicated. At 120 days after the first injection with cII, the mice were sacrified, and their paws were dissected, fixed in $10 \%$ formaldehyde $(\mathrm{pH} 7.4)$ and then embedded in paraffin wax. Serial sections $(5 \mathrm{~mm})$ of the joints were prepared and then stained using hematoxylin to evaluate pannus formation, synovial cell infiltrate and cartilage/bone erosion.

The data are representative of three independent experiments. The clinical scores and paw thickness were analyzed using a two-way analysis of variance. The incidence of CIA was analyzed using Fisher's exact test.

\section{$\mathrm{X}$-ray radiographic assessment}

CA1-Tg mice, wild-type mice, PADI4-Tg mice and CA1$\mathrm{Tg}$ mice treated with BSA were evaluated at 120 days after the first injection of CII. The mice were anesthetized and irradiated using a digital mammography X-ray as described by Zähringer [14]. Digital images of the vertebrae and joints were obtained using the following exposure parameters: mammography film, $23 \mathrm{kV}$ and 32 mAs; Inc, -2; AGD, 0.52 mGy; ESE, 1.36 mGy. This experiment was completed in the Radiological Department of the Shandong Tumor Hospital.

\section{Real-time PCR}

Total RNA was extracted from animal tissues using a total RNA kit (Omega, USA) according to the manufacturer's protocol. The concentrations of total RNA were determined using a spectrophotometer. The cDNA was prepared with $500 \mathrm{ng}$ of total RNA from each sample using oligo-dT primers and the PrimeScriptTM RT-PCR Kit (TaKaRa, Japan). Quantitative PCR analysis was performed using a LightCycler 480 thermocycler (Roche). Taqman real-time PCR was conducted in $10 \mu$ reaction mixtures containing $5 \mu \mathrm{l}$ of SYBR Green (Toyobo, Japan), $1 \mu \mathrm{l}$ of each primer, $1 \mu \mathrm{l}$ of cDNA and $2 \mu \mathrm{l}$ of $\mathrm{H}_{2} \mathrm{O}$. The optimized thermal cycling program was as follows: step 1, $95^{\circ} \mathrm{C}$ for $180 \mathrm{~s}$; step $2,95^{\circ} \mathrm{C}$ for $10 \mathrm{~s}, 59^{\circ} \mathrm{C}$ for $10 \mathrm{~s}$ and $72^{\circ} \mathrm{C}$ for $25 \mathrm{~s}$ ( 45 cycles); and step 3 , a melting curve analysis over $59-95^{\circ} \mathrm{C}$ in $0.5^{\circ} \mathrm{C}$ increments. The specificity of the individual amplification reactions was assessed by examining the melting curves to confirm the presence of a single gene-specific peak with the characteristic melting temperature of the expected product. The primers for CA1 are as follows: $5^{\prime}$-GCTACAGGCTCTTTCAGTT- ${ }^{\prime}$ and 5'-GACTCCATCCACTGTATGTT-3'. The PCR results were normalized to the level of GAPDH expression. Two reactions were performed simultaneously for each sample. One reaction was performed to determine the expression of mRNA of the target gene, and the second reaction was performed to determine the level of GAPDH. The experiment was performed in triplicate, and the PCR products were confirmed using a melting-curve analysis. The relative expression of mRNA was calculated using the comparative threshold cycle $(\mathrm{Ct})$ method according to the following formula: Ratio $=2^{-\Delta \Delta \mathrm{Ct}}=2^{-\Delta \mathrm{Ct}}$ (sample)- $\Delta \mathrm{Ct}$ (control) where $\Delta \mathrm{Ct}=\mathrm{Ct}$ of the target genes $-\mathrm{Ct}$ of the endogenous control gene (GAPDH). The relative target gene expression was calculated by normalizing to the expression of GAPDH mRNA. The copy number of the target mRNA in each sample was calculated automatically using data analysis software. The levels of CA1 are expressed as the median and range. Significant differences were assessed using the Mann-Whitney U-test where $\mathrm{p}<0.05$ was considered statistically significant.

\section{Western blotting}

Animal tissues were homogenized in RIPA buffer (Beyotime, China) supplemented with protease and phosphatase inhibitors on ice and centrifuged at 16,000 $\mathrm{g}$ for $5 \mathrm{~min}$ at $4^{\circ} \mathrm{C}$. The supernatant was collected, and the protein concentration was determined using the BCA Protein Assay Kit (Beyotime, China). Thirty micrograms of total protein was separated on a $12 \%$ SDS-polyacrylamide gel and transferred onto a PVDF membrane. The membrane was rinsed with wash solution and incubated overnight at $4{ }^{\circ} \mathrm{C}$ with anti-human carbonic anhydrase I antibody (Santa Cruz, USA) at a dilution of 1:500. The antibody was prepared by immunizing a mouse with a peptide comprising carbonic anhydrase I amino acids 33-80, which are near to the N-terminus. The manufacturer confirmed no crossreactivity with other carbonic anhydrases. Immunosignals were visualized using the Protein Detector BCIP/NBT Western Blotting Kit (Beyotime, China) following the manufacturer's instructions. The quantification was conducted using ImageQuant 5.2 software. To normalize the sample loading, a separate membrane was prepared in the same manner and was probed using an anti-GAPDH antibody (Santa Cruz, USA).

\section{Statistical analyses}

All data are presented as the mean \pm SD. Comparisons between two groups were performed using unpaired Student's t-tests. Multiple intergroup comparisons were performed using one-way ANOVAs. The incidence of mice that developed the disease was analyzed using Fisher's exact test. We considered $p$ values $<0.05$ to be significant. 


\section{Results}

Generation of CA1-Tg mice

To determine the potential role of CA1 in arthritis and AS, C57BL/6J transgenic mice that over-expressed CA1 were generated. Five transgenic founders (\#1, \#2, \#4, $\# 33$, and \#37) were generated and identified based on a PCR analysis of their genomic DNA. The transgenic founder (F0) mice were mated with wild-type C57BL/6J mice to produce the $\mathrm{F} 1$ generation, and the CMV/CA1 gene was identified based on a PCR analysis of their genomic DNA (data not shown). These founder mice did not show significant differences of phenotype, growth rate, body weight and fertility among them. All of five founders were used to generate F2.

\section{CA1 expression in the transgenic mice}

CA1 protein levels were determined in the lung, kidney, spleen, thymus and liver of these transgenic mice $(n=5$, 8 weeks old) using western blotting. CA1 protein $(29 \mathrm{kDa})$ levels were 3.05 -fold $(\mathrm{p}=0.02)$ higher in the spleen, 1.8-fold ( $\mathrm{p}=0.005$ ) higher in the liver, and 2.04fold $(\mathrm{p}=0.016)$ higher in the thymus of CA1-Tg mice compared with wild-type mice $(n=6,8$ weeks old). The expression of CA1 was unchanged, low or was not detected in other organs of the CA1-Tg mice, such as the lungs $(\mathrm{p}=0.07)$ and kidneys $(\mathrm{p}=0.767)$, compared with controls. The levels of CA1 protein in the various organs of the PADI4-Tg mice $(n=6,8$ weeks old) were similar to those of the wild-type mice. These results are shown in Figure $1 \mathrm{~A}$ and $\mathrm{B}$.

The level of CA1 mRNA in the synovial tissues of these F1 mice $(n=5)$ was quantified using real-time PCR. Compared with the expression of CA1 in synovial samples from wild-type mice $(n=6)$ and PADI4-Tg mice $(n=6)$, CA1 mRNA was increased 1.85 -fold $(\mathrm{p}=0.016)$ in the tissues of CA1-Tg mice. There was no significant difference in CA1 mRNA level of the synovial membranes between PADI4-Tg mice and wild-type mice $(p=0.145)$. These results are shown in Figure $1 \mathrm{C}$.

\section{Collagen-induced arthritis in transgenic mice over- expressing CA1}

The arthritic incidence and the CIA clinical scores of CA1-Tg mice were compared with those of PADI4-Tg mice and wild-type mice. CA1-Tg mice that were injected with BSA were also used as controls. The incidence of CIA was $60 \%(6 / 10)$ in CA1-Tg mice, $20 \%(2 / 10)$ in PADI4-Tg mice, $20 \%(2 / 10)$ in wild-type mice and $0 \%$ $(0 / 10)$ in CA1-Tg mice injected with BSA on the 84th day after the first injection $(\mathrm{p}=0.017)$ (Figure 2A).

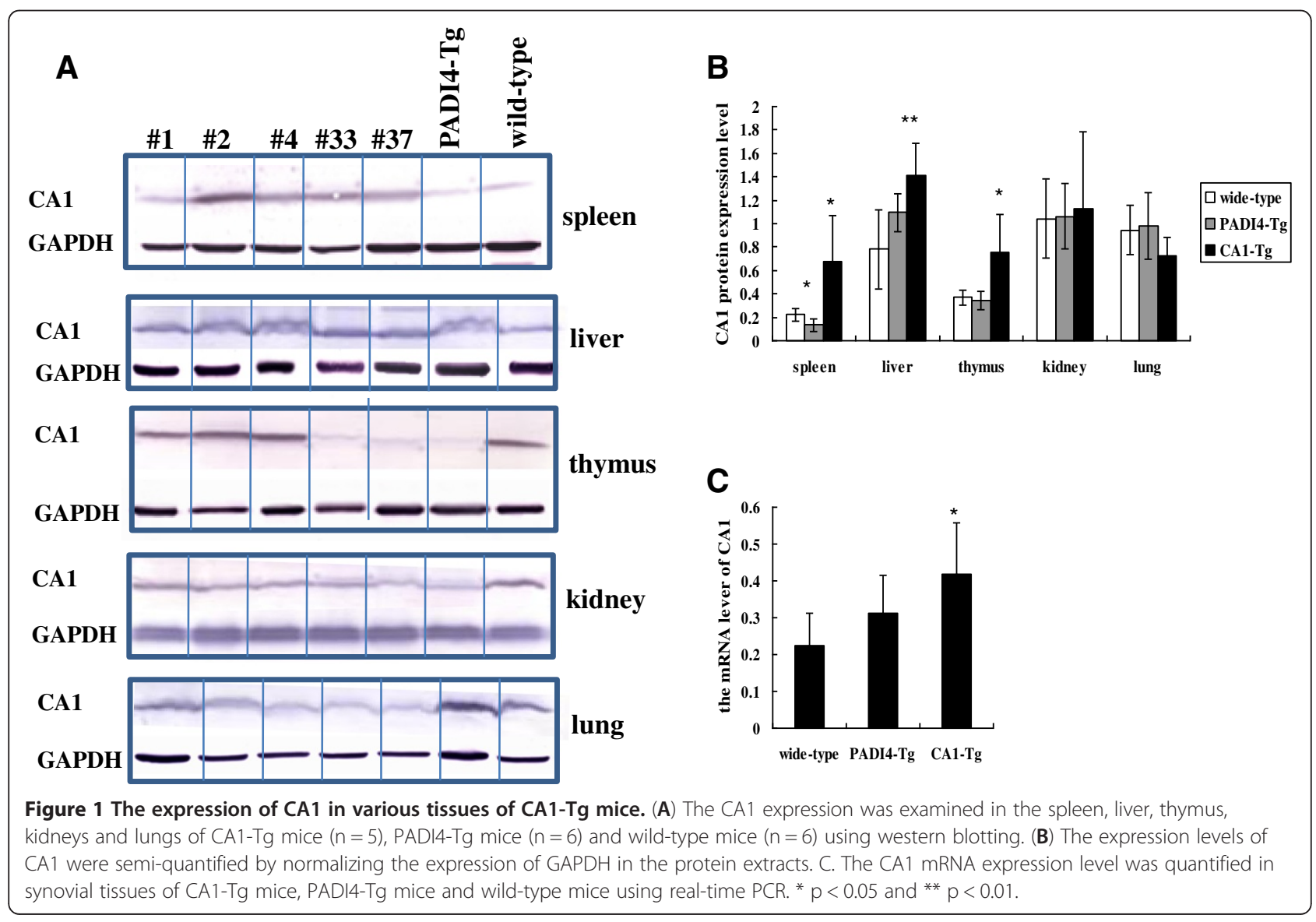




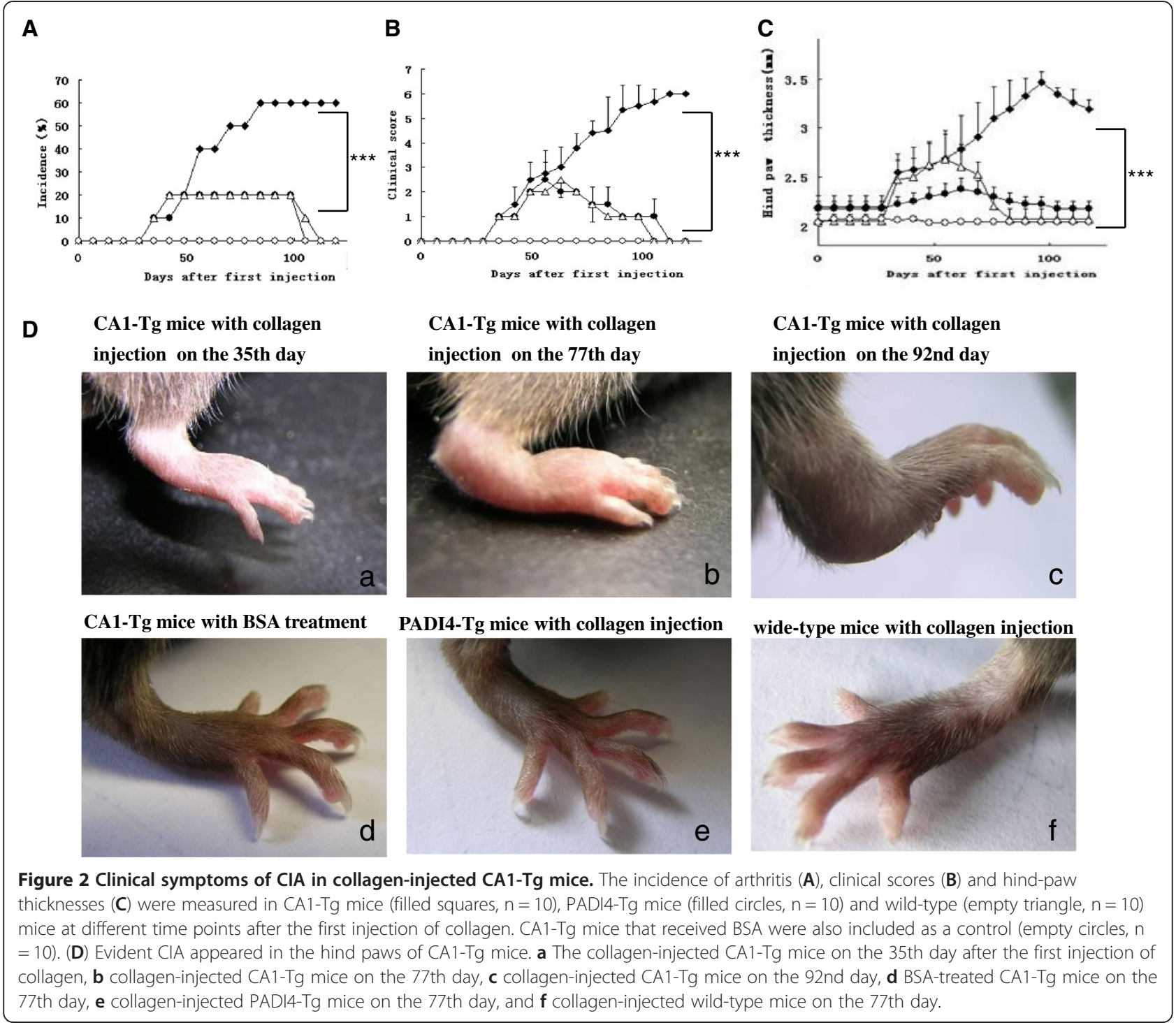

The arthritis severity score was $5.5 \pm 0.84$ for the CA1$\mathrm{Tg}$ mice on the 98th day after the first injection, but the score was less than 2 for the wild-type mice and the PADI4-Tg mice under the same conditions. No clinical signs of arthritis were found in the CA1-Tg mice treated with BSA ( $p=0.00001$, Figure $2 B)$.

The hind-paw thickness of the CA1-Tg mice was $3.46 \pm$ $0.11 \mathrm{~mm}$, which was thicker than that of PADI4-Tg mice $(2.23 \pm 0.08 \mathrm{~mm})$, wild-type mice $(2.08 \pm 0.06 \mathrm{~mm})$ and BSA-treated CA1-Tg mice $(2.04 \pm 0.07 \mathrm{~mm} ; \mathrm{p}=0.00001$, Figure $2 \mathrm{C}$ ). The hind paws of the CA1-Tg mice showed significant edema, redness and ankylosis with pronounced loss of function on the 92nd day after the first injection of collagen, whereas the hind paws of all immunized PADI4$\mathrm{Tg}$ mice and wild-type mice appeared normal (Figure 2D).

Five mice were selected randomly from the collageninjected CA1-Tg mice with CIA $(\mathrm{n}=5)$, the PADI4-Tg mice $(n=5)$, the wild-type mice $(n=5)$ without CIA and the BSA-treated CA1-Tg mice $(n=5)$ to examine joint tissue structure. Histological examination detected evident cell hyperplasia and diffused lymphoid cell infiltrate; fibrin deposition; cartilage-surface erosion; and bone destruction in the joints of the paw, ankle, knee and sacroilium of all five CA1-Tg mice with CIA. The joints of the PADI4-Tg mice and the wild-type mice that were injected with collagen and the CA1-Tg that were injected with BSA exhibited a smooth articular surface. No significant synovial inflammation or cartilage surface erosion was observed in these controls. These results are shown in Figure 3.

The destruction of the joint tissue described above in the collagen-treated CA1-Tg mice $(n=5)$, collagentreated PADI4-Tg mice without CIA $(n=5)$, collagentreated wild-type mice $(\mathrm{n}=5)$ and BSA-treated CA1-Tg 


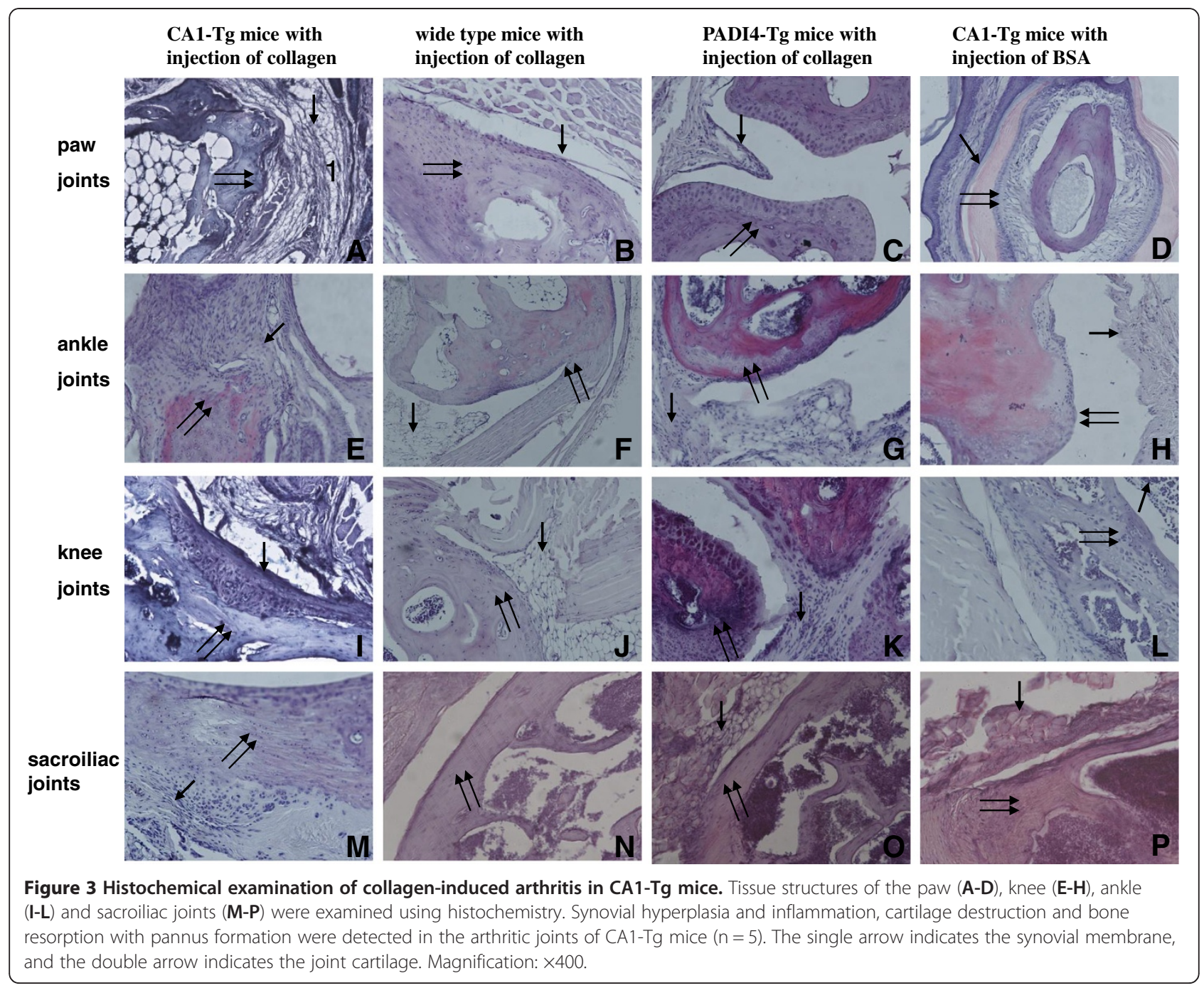

mice $(n=5)$ was examined using digital mammography $\mathrm{X}$-ray imaging. In collagen-treated $\mathrm{CA} 1-\mathrm{Tg}$ mice, the contours of the cartilaginous tissues were diffuse due to chondrophyte formation. Progression of spondylitis was observed in each CA1-Tg animal that developed CIA. In the three CA1-Tg mice treated with collagen, the disk space disappeared, and chondrophyte/osteophyte fusion with the neighboring vertebral bodies was observed that replaced the original intervertebral disk. In the collagentreated PADI4-Tg mice, the wild-type mice and the BSA-treated CA1-Tg mice, the growth plates were nor$\mathrm{mal}$, and the end plates of the vertebral bodies appeared as sharp, solid lines. In addition, the hind paws of the injected CA1-Tg mice treated with CIA exhibited bone formation in the ankle joints. In contrast, the hind paws of the collagen-immunized PADI4-Tg mice and wildtype mice as well as the BSA-treated CA1-Tg mice appeared similar to those of wild-type mice that had not received any treatment and displayed no apparent bone formation. These X-ray results are shown Figure 4.
The above experiment was repeated for 3 times and we got similar results. The data are representative of three independent experiments. All F2 from different founders were used for the experiment. There was no significant difference among these F2.

\section{Discussion}

In our study, transgenic mice that over-expressed CA1 were markedly susceptible to collagen treatment and showed a high incidence and serious symptoms of arthritis. X-ray images revealed that the disk space in the spinal regions had disappeared, that neighboring vertebral bodies had fused and that the bone density had increased in the paws and spines of collagen-immunized CA1-Tg mice. In contrast to CA1-Tg mice, clinical and histological evaluation showed a normal progression of disease parameters in the collagen-immunized wild-type mice and PADI4-Tg mice. The growth plates were normal in PADI4-Tg and wild-type mice. Histological examination also revealed obvious cartilage loss, synovial inflammation 


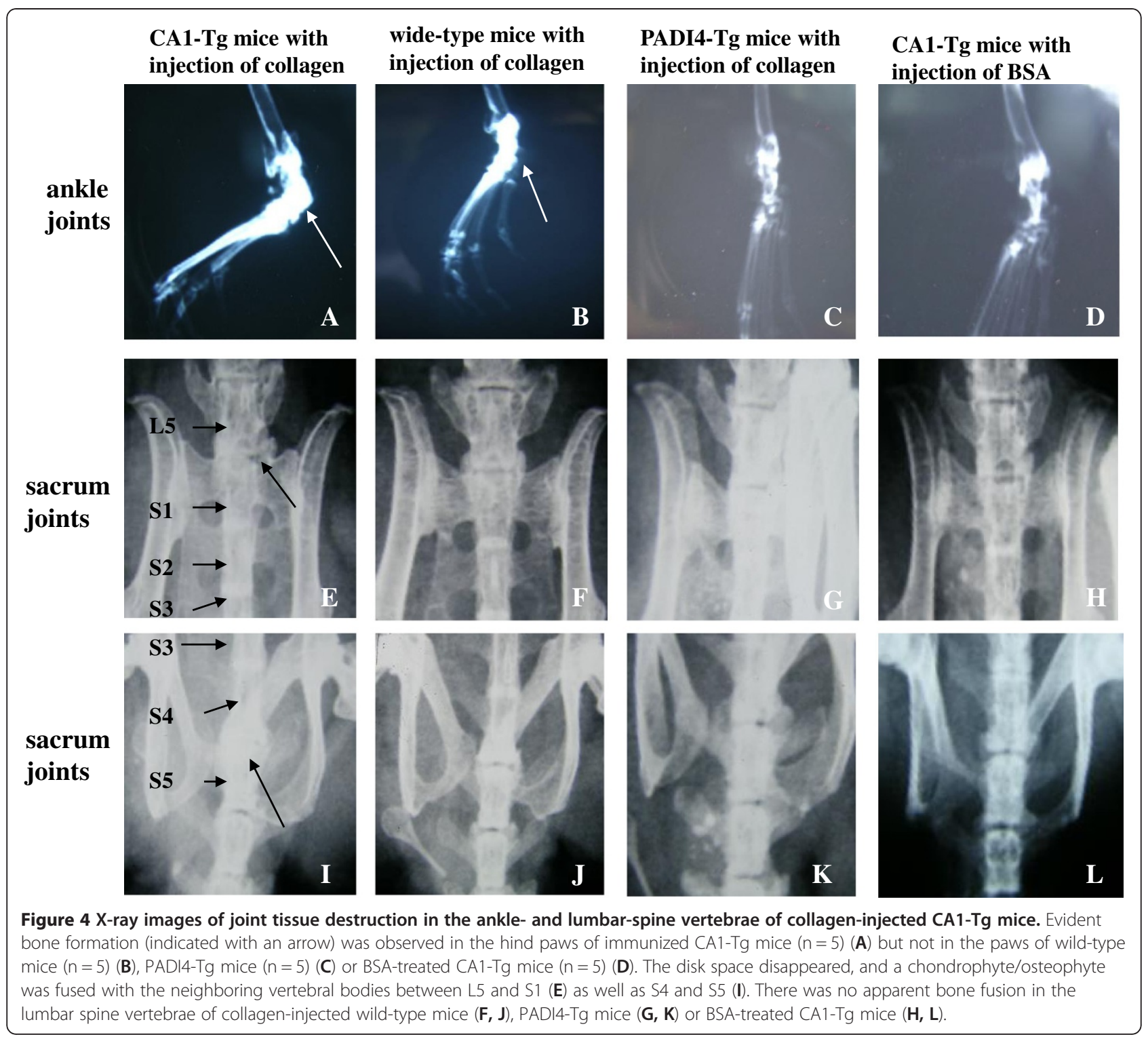

and bone destruction in the paw, ankle, knee and sacroiliac joints of CA1-Tg mice with CIA but not in the PADI4-Tg and wild-type mice. Thus, our study suggests that over-expression of CA1 may accelerate the joint inflammation and tissue destruction of the mice.

The inflammation, bone erosion and ossification of sacroiliac joints and the spine are histopathological features of AS [15]. Mark et al. established transgenic mice that expressed human HLA-B27. Using radiographic and histological techniques, they detected severe axial skeletal kyphosis and ankylosis accompanying an inflammatory and fibrotic process at the end plates and enthesis [16]. Their observations were similar to the observations of our animal model. These animals developed a spontaneous multisystem disorder that resembles the spondylitis observed in AS. Although the histological features of the synovial membranes of the peripheral joints in AS are similar to those of RA, fibroblastic proliferation, intimal cell hypertrophy, diffuse lymphocyte and histiocyte infiltration and the presence of fibrin were less marked in the joint tissues of AS than in joint tissues of definite RA. Decreased intimal cell hypertrophy and fibroblastic proliferation were observed in synovial tissues of AS compared with RA [17]. In the synovial tissue of CA1$\mathrm{Tg}$ mice with CIA, intimal cell hypertrophy and fibroblastic proliferation were relatively low and the lining layer was thin. Thus, the transgenic mice that overexpressed CA1 showed more AS symptoms than RA symptoms following treatment with collagen.

Joint tissue destruction is a hallmark of inflammatory joint diseases, such as RA and AS. Despite considerably different pathologies, there are certain similarities among 
the diseases. In particular, inflammation and bone and cartilage destruction are the driving force for the structural changes in the diseased joints. We recently reported that the gene encoding CA1 is susceptible to AS and RA [10]. Thus, it is not surprised that we observed more AS symptom in CA1-Tg following collagen treatment. CIA is generally used to investigate mechanism of RA. Gillet et al. studied 40 inbred female Wistar Furth rats. At 2 weeks after immunization with native human type-II collagen, the rats showed polyarthritis that progressed to ankylosis associated with ossifying enthesopathy and periosteal new bone formation. Inflammatory nodules of the tail appeared after 2 months, with radiological and histopathological aspects of multistage spondylodiscitis [18]. Their finding supports the fact that collagen-induced arthritis may be a relevant model of peripheral and axial ossifying enthesopathy.

In the present study, we did not investigate the site of genome incorporation of CA1 in the transgenic mice. We prepared a series of controls including collagen-injected PADI4-Tg, BSA-injected CA1-Tg and collagen-injected wild-type. These controls showed low joint inflammation and no joint inflammation in their joint tissues. The controls also showed normal expression of CA1 in various organs of the mice. On the other hand, CA1-Tg showed significant joint inflammation following injection of collagen II. These results suggest that the CMV promoter and neighboring genes did not put an effect on the CA1 expression in CA1-Tg and did not take influence on the result of the study.

Our study had demonstrated that CA1 stimulates calcium salt precipitation and cell calcification which could explain the higher incidence of the disease in CA1 transgenic mice which can explain the joint tissue destruction [5]. We had also reported that CA1 encoding gene has a strong association with AS [10]. The present study detected high expression of CA1 in spleen, thymus and synovial tissues. But it is not sure if CA1 has any effect on adaptive immune response which could also explain the higher incidence of the disease in CA1 transgenic mice. Recently, Yamanishi H, et al. treated SCID mice with CA1-pulsed regulatory dendritic cells. The treated mice had higher mRNA expression of IL-10 and TGF- $\beta 1$ and lower IL-17 mRNA expression [19].

\section{Conclusion}

This study investigated the pathogenic role of CA1 using a transgenic animal model. Transgenic mice that overexpressed CA1 show an enhanced susceptibility to CIA. Histochemistry and X-ray analysis also demonstrated similar joint destruction to that found in AS. This finding may provide additional understanding of the pathogenic mechanism underlying the rheumatic disease.

\section{Abbreviations}

CA1: Carbonic anhydrase I; CIA: Collagen induced arthritis; CA1-

Tg: Transgenic mice with an over-expression of CA1; PADI4-Tg: Transgenic mice over-expressing PADI4; BSA: Bovine serum albumin; AS: Ankylosing spondylitis; OA: Osteoarthritis; cll: Collagen type II.

\section{Competing interests}

The authors declare that they have no competing interests.

\section{Authors' contributions}

XC had full access to all of the data from this study and takes responsibility for the integrity of the data and the accuracy of the data analyses. YZ, LW and HX performed animal experiment. YZ, LW and WZ performed western blots, immunohistochemistry and real time PCR. All authors have read and approved the final manuscript for publication.

\section{Acknowledgement}

This study was supported by the National Natural Science Foundation of China (NTFC 30972720), the National Basic Research Program of China (2010CB529105) and a Shandong Taishan Scholarship.

\section{Author details}

${ }^{1}$ Medical Research Center of Shandong Provincial Qianfoshan Hospital, Shandong University, Jingshi road 16766, Jinan, Shandong 250014, P. R. China. ${ }^{2}$ Research Center for Medical Biotechnology, Shandong Academy of Medical Sciences, Jingshi road 18877, Jinan, Shandong 250062, P. R. China. ${ }^{3}$ The Secondary People's Hospital of Jinan, Jingyi road 148, Jinan, Shandong 250001, P. R. China. ${ }^{4}$ Department of Pharmacy, Shandong Provincial Tumor Hospital, Jiyan road 440, Jinan, Shandong 250117, P. R. China.

Received: 21 July 2012 Accepted: 17 December 2012

Published: 20 December 2012

\section{References}

1. Zhang X, Aubin JE, Inman RD: Molecular and cellular biology of new bone formation: insights into the ankylosis of ankylosing spondylitis. Curr Opin Rheumatol 2003, 15:387-393.

2. Schett $\mathrm{G}$ : Bone formation versus bone resorption in ankylosing spondylitis. Adv Exp Med Biol 2009, 649:114-121.

3. Grisar J, Bernecker PM, Aringer M, Redlich K, Sedlak M, Wolozcszuk W, Spitzauer S, Grampp S, Kainberger F, Ebner W, Smolen JS, Pietschmann P: Ankylosing spondylitis, psoriatic arthritis, and reactive arthritis show increased bone resorption, but differ with regard to bone formation. J Rheumatol 2002, 29:1430-1436.

4. Chen WS, Chen CH, Lin KC, Tsai CY, Liao HT, Wang HB, Chen YK, Yang AH, Chen TC, Chou CT: Immunohistological features of hip synovitis in ankylosing spondylitis with advanced hip involvement. Scand J Rheumatol 2009, 38:154-155.

5. Chang X, Han J, Zhao Y, Yan X, Sun S, Cui Y: Increased expression of carbonic anhydrase I in the synovium of patients with ankylosing spondylitis. BMC Musculoskelet Disord 2010, 11:279.

6. Chang $X$, Yan $X$, Zhang Y: Treat ankylosing spondylitis with methazolamide. Int J Med Sci 2011, 8:413-419.

7. Supuran CT: Carbonic anhydrases-an overview. Curr Pharm Des 2008, 14:603-614

8. Parissa M, Koorosh A, Nader M: Investigating the Application of Enzyme Carbonic Anhydrase for $\mathrm{CO}_{2}$ sequestration purposes. Ind Eng Chem Res 2007, 46:921-926.

9. Ramanan R, Kannan K, Sivanesan SD: Bio-sequestration of carbon dioxide using carbonic anhydrase enzyme purified from Citrobacter freundii. World J Microbiol Biotechnol 2009, 25:981-987.

10. Chang X, Zheng Y, Yang Q, Wang L, Pan J, Xia Y, Yan X, Han J: Carbonic anhydrase I (CA1) is involved in the process of bone formation and is susceptible to ankylosing spondylitis. Arthritis Res Ther 2012, 14:R176.

11. Suzuki A, Yamada R, Chang X, Tokuhiro S, Sawada T, Suzuki M, Nagasaki M, Nakayama-Hamada M, Kawaida R, Ono M, Ohtsuki M, Furukawa H, Yoshino S, Yukioka M, Tohma S, Matsubara T, Wakitani S, Teshima R, Nishioka Y, Sekine A, lida A, Takahashi A, Tsunoda T, Nakamura Y, Yamamoto K: Functional haplotypes of PADI4, encoding citrullinating enzyme peptidylarginine eiminase 4 , are associated with rheumatoid arthritis. Nat Genet 2003, 34:395-402. 
12. Plück A, Klasen C: Generation of chimeras by microinjection. Methods Mol Biol 2009, 561:199-217.

13. von Delwig A, Altmann DM, Charlton FG, McKie N, Isaacs JD, Holmdahl R, Robinson JH: T cell responses to a non-glycosylated epitope predominate in type II collagen-immunised HLA-DRB1*0101 transgenic mice. Ann Rheum Dis 2007, 66:599-604.

14. Zähringer M, Krug B, Kamm KF, Wassmer G, Hellmich M, Winnekendonk G, Andermahr J, Gossmann A, Lackner KJ: Detection of porcine bone lesions and fissures: comparing digital selenium, digital luminescence, and analog film-screen radiography. AJR Am J Roentgenol 2001, 177:1397-1403.

15. Tam LS, Gu J, Yu D: Pathogenesis of ankylosing spondylitis. Nat Rev Rheumatol 2010, 6:399-405.

16. Crew MD, Effros RB, Walford RL, Zeller E, Cheroutre H, Brahn E: Transgenic mice expressing a truncated peromyscus leucopus TNF-a gene manifest an arthritis resembling ankylosing spondylitis. J Interferon Cytokine Res 1998, 18:219-225.

17. Revell PA, Mayston V: Histopathology of the synovia membrane of peripheral joints inankylosing spondylitis. Ann Rheum Dis 1982. 41:579-586.

18. Gillet $P$, Bannwarth $B$, Charrière $G$, Leroux $P$, Fener $P$, Netter $P$, Hartmann DJ, Péré $P$, Gaucher A: Studies on type II collagen induced arthritis in rats: an experimental model of peripheral and axial ossifying enthesopathy. J Rheumatol 1989, 16:721-728.

19. Yamanishi H, Murakami H, Ikeda Y, Abe M, Kumagi T, Hiasa Y, Matsuura B, Onji M: Regulatory dendritic cells pulsed with carbonic anhydrase I protect mice from colitis induced by CD4 + CD25- T cells. J Immunol 2012, 188:2164-2172.

doi:10.1186/1471-2474-13-256

Cite this article as: Zheng et al:: Transgenic mice over-expressing carbonic anhydrase I showed aggravated joint inflammation and tissue destruction. BMC Musculoskeletal Disorders 2012 13:256.

\section{Submit your next manuscript to BioMed Central and take full advantage of:}

- Convenient online submission

- Thorough peer review

- No space constraints or color figure charges

- Immediate publication on acceptance

- Inclusion in PubMed, CAS, Scopus and Google Scholar

- Research which is freely available for redistribution 